\title{
A Consideration on Common Path Length and Single Stairway
}

\author{
ICHIRO HAGIWARA, TAKEYOSHI TANAKA and YOSHIO MIMURA \\ Building Research Institute, Ministry of Construction \\ 1 Tatehara, Tsukuba-shi, Ibaraki-ken 305, Japan
}

\begin{abstract}
Usually, it is required by building codes that two or more escape routes be available from every point in a building for the purpose of assuring at least one available egress route should the other happen to be blocked by fire. The limitation of common path length and the requirement of two or more stairways for buildings exceeding certain size are typical examples of such requirements. Despite their vital influence on building design, lucid explanation has not been given to the adequacy of the provisions. In this paper, the meaning of the code requirements on common path length and number of stairways are discussed, and the criterion that may be used as an alternative to such prescribed standards is derived based on the consideration of the expected number of occupants unable to escape.
\end{abstract}

KEYWORDS: means of escape, two-way escape routes, common path of travel, single stairway, performance code

\section{INTRODUCTION}

It is commonly deemed to be important for safe evacuation in building fire that two or more escape routes are arranged in different directions. Usually, it is required by building codes that two or more escape routes be available from every point in a building. This intends to assure at least one available egress route should the other happen to be blocked by fire.

The limitation of common path length and the requirement of two or more stairways for buildings exceeding certain size are typical examples of such requirements. Purely from the viewpoint of safe escape, it is desirable that the common path is as short as possible, and that two or more stairways are provided for every building. But such ideal plans are not always realized in real buildings because of the constraints of economy and convenience in normal use. However ideal they may be from the fire safety point of view, it is difficult to oblige to sacrifice everyday benefits excessively since fires are no longer so frequent threats in developed countries.

In building codes, a certain length of common path and single stairway are allowed under some conditions as a result of compromise between the safety and the building economy in the broad 
sense. Still, building plans are significantly affected by such requirements. Despite the vital influence on building design, lucid explanation has not been given to the adequacy of the provisions.

In this paper, the meaning of the code requirements on common path length and number of stairway are discussed, and the criterion that may be used as an alternative to such prescribed standards is derived based on the consideration of the expected number of occupants unable to escape.

\section{PROVISIONS OF COMMON PATH LENGTH IN THE EXISTING REGULATIONS}

\subsection{Provisions for Arrangement of Exits}

Provisions for arrangement of escape routes in existing codes dealing with fire safety include maximum travel distance to the nearest exit, minimum distance between exits or stairways, maximum length of dead end corridor etc. as well as limitation of common path length.

The provisions on maximum travel distance and common path length in several countries are compared in Table $1^{1}$. The values of maximum travel distance in the countries vary significantly depending on building features such as occupancy, number of floors, sprinkler installation and so forth. Common path length is likely to be determined in connection with, at roughly one half of, maximum travel distance.

\subsection{Maximum Travel Distance}

Maximum travel distance is the limit of distance to cover from a point on a floor to an exit to outdoor or a protected escape path such as a smokeproof tower. There are two ways of measurement for the maximum travel distance depending on the code, that is, one which measure from the remotest point including the interior of a room, and the other which measure from the doorway of a room.

The meaning of maximum travel distance in the context of escape in fire is interpreted as either of the following ${ }^{2}$ :

TABLE 1 Arrangement of means of escape

\begin{tabular}{|c|c|c|c|c|c|}
\hline & Australia & France & Japan & U.K. & U.S. \\
\hline 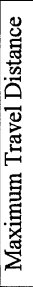 & \begin{tabular}{|ll} 
a)Apartment, Hotel & N.R. \\
b)Assembly & $60 \mathrm{~m}$ \\
in room & $40 \mathrm{~m}$ \\
door-exit & $20 \mathrm{~m}$ \\
c)Hospital(ward) \\
\multicolumn{3}{r}{$\quad 30 \mathrm{~m}$} \\
d) others & $40 \mathrm{~m}$
\end{tabular} & $\begin{array}{l}\text { a) General } 40 \mathrm{~m} \\
\text { b) from unprotected } \\
\text { stairways } 30 \mathrm{~m} \\
\text { c) from dead-end } 30 \mathrm{~m} \\
\text { d) Hotel } \\
\text { door-exit } 40 \mathrm{~m} \\
\text { e) Apartment } \\
\text { smoke controlled } \\
\text { door-exit } 15 \mathrm{~m} \\
\text { open-air corridor } \\
\text { door-exit N.R. }\end{array}$ & $\begin{array}{l}\text { a) Shop, Office } \\
=<14 \text { th stories } 30 \mathrm{~m} \\
>=15 \text { th stories } 20 \mathrm{~m} \\
\text { b) others } \\
=<14 \text { th stories } 50 \mathrm{~m} \\
>=15 \text { th stories } 40 \mathrm{~m} \\
\\
* \text { interior finished with } \\
\text { non-combustible } \\
\text { material } \quad+10 \mathrm{~m}\end{array}$ & $\begin{array}{l}\text { number of direction } \\
\qquad<1>/<2> \\
\text { a) Assembly, school } \\
15 \mathrm{~m} / 32 \mathrm{~m} \\
\text { b) Hospital } \\
\quad 9 \mathrm{~m} / 18 \mathrm{~m} \\
\text { c) Hotel } \\
\text { bedroom } 9 \mathrm{~m} / 18 \mathrm{~m} \\
\text { elsewhere } 18 \mathrm{~m} / 35 \mathrm{~m} \\
\text { d) Apartment } \\
\text { in room } 9 \mathrm{~m}\end{array}$ & $\begin{array}{lr}\text { a) Assembly45m }(60 \mathrm{~m}) \\
\text { b) School } & 45 \mathrm{~m}(60 \mathrm{~m}) \\
\text { c) Hospital } & (60 \mathrm{~m}) \\
\text { in room } & 23 \mathrm{~m}(38 \mathrm{~m}) \\
\text { door- } & 30 \mathrm{~m}(60 \mathrm{~m}) \\
\text { d) Hotel, } & \text { Apartment } \\
\text { in room } & 23 \mathrm{~m}(38 \mathrm{~m}) \\
\text { door- } & 30 \mathrm{~m}(60 \mathrm{~m}) \\
\text { e) Shop } & 30 \mathrm{~m}(60 \mathrm{~m}) \\
\text { f) Office } & 60 \mathrm{~m}(91 \mathrm{~m})\end{array}$ \\
\hline & $\begin{array}{l}\text { a) Apartment, Hotel } \\
\text { door-exit } 6 \mathrm{~m} \\
\text { others } 20 \mathrm{~m} \\
\text { b) Hospital(ward) } \\
\quad 12 \mathrm{~m} \\
\text { c) Shop, Office } 30 \mathrm{~m} \\
\text { d) single stairways } \\
\\
\text { e) others } \quad 30 \mathrm{~m} \\
\text { en }\end{array}$ & $\begin{array}{c}\text { from door at dead-end } \\
10 \mathrm{~m}\end{array}$ & $\begin{array}{l}1 / 2 \text { of maximum travel } \\
\text { distance }\end{array}$ & $\begin{array}{l}\text { unit door-exit } \\
7.5 \mathrm{~m} / 30 \mathrm{~m} \\
\text { e) Shop, Office } \\
18 \mathrm{~m} / 45 \mathrm{~m}\end{array}$ & $\begin{array}{l}\text { a) Assembly 6.1m(6.1m) } \\
\text { area }=<50 \text { Ps. } \\
\text { b) } 23 \mathrm{~m}(23 \mathrm{~m}) \\
\text { b)hool } 23 \mathrm{~m}(23 \mathrm{~m}) \\
\text { c) Hospital N.R. } \\
\text { d) Hotel, Apartment } \\
\text { except in room } \\
10.7 \mathrm{~m}(15 \mathrm{~m}) \\
\text { e) Shop } 23 \mathrm{~m}(30 \mathrm{~m}) \\
\text { f) Office } 23 \mathrm{~m}(30 \mathrm{~m}) \\
\text { one tenant=<30Ps. } 30 \mathrm{~m}\end{array}$ \\
\hline
\end{tabular}


(1) The limit of the distance which evacuees can manage to reach a stairway running through a smoke clogged space such as a corridor etc.

(2) The limit of the distance which evacuees can manage to reach a stairway before the escape routes such as a corridor has been smoke clogged.

In any case, the essential meaning of maximum travel distance is the limitation of travel time to a protected stairway in view of safety from smoke. In this sense, it may be allowed to relax the limitation of maximum travel distance if the danger by smoke is considered to be low. In fact, the distance is relaxed according to the degree of fire retardation of interior linings in Japan, and by sprinkler installation in the U.S.A. In France, there is no limitation on the distance for open-air corridors in apartment buildings.

\subsection{Objective of Limitation of Common Path Length}

Common path length is the distance from where egress start to where two or more escape directions are available. Typical concept of common path is illustrated in Figure 1a. Common path length is usually measured from the remotest point in a room, but may be measured from the doorway of a room in some cases, such as collective dwellings and lodging facilities.

In actual buildings, common path appears in such plans as shown in Figure $1 \mathrm{~b}$ more frequently than the plan in Figure 1a. In such a case, evacuees only have to cover the distance of the common path length to reach a stairway as long as they do not fail to find the stairway, so practically the limitation of common path length induces the reinforcement of maximum travel distance.

The role of the limitation of common path length is different from that of maximum travel distance. The basic concept of common path length is shown by Figure 1a. Obviously, it is not enough to cover the common path to get to a safe place such as a stairway. It is not common path length but maximum travel distance that has to be limited if the objective is to avoid or mitigate hazards due to smoke.

The objective of the limitation of common path length is considered to reduce the risk that escape is blocked by a fire which happens to occur on the egress path to a stairway or other places of final safety. The typical scenario will be, as shown in Figure 2, that a fire breaks out in a room along a one way corridor and the flames or hot gases ejecting out from the doorway impedes the passage of occupants in rooms located at the opposite side of a stairway. The meaning of the limitation of common path length is to limit the number of the occupants who may lose the only escape means.

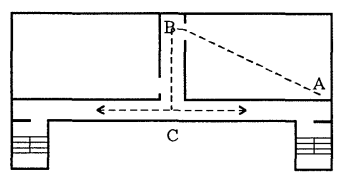

a. Typical concept

AC: common path of travel

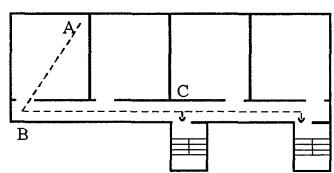

b. Actual arrangement

$\mathrm{BC}$ : common path of travel in corridors

FIGURE 1 Examples of common path of travel

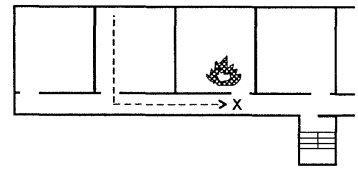

FIGURE 2 A fire blocks only one escape route to a stairway 
TABLE 2 Condition allowed in case of single stairway

\begin{tabular}{|c|c|c|c|c|c|}
\hline & Australia & France & Japan & U.K. & U.S. \\
\hline & $\begin{array}{l}\text { a) }=<6 \text { stories or } \\
\quad=<25 \mathrm{~m} \text { height } \\
\text { Hospital, Assembly, } \\
\text { School } \\
\text { b) }=<6 \text { stories or } \\
=<25 \mathrm{~m} \text { height } \\
\& \text { any story }>50 \mathrm{Ps} . \\
\text { except } \\
* \text { ward floor } \\
* \text { preschool } \\
* \text { primary or } \\
\text { secondary school }\end{array}$ & $\begin{array}{l}\text { for story or part of } \\
\text { story } \\
1)=<19 \mathrm{Ps} . \quad 1 \\
2)=<50 \mathrm{Ps} \text {. 1+sub } \\
\text { Apartment } \\
\text { a) combinations of } \\
\text { stairways and } \\
\text { corridors opened to } \\
\text { the air or with smoke } \\
\text { control } \\
\text { b) stairways with } \\
\text { smoke control }\end{array}$ & $\begin{array}{l}=<5 \text { th floor \& } \\
\text { a) on } 3-5 \text { th floor } \\
\& \mathrm{~A}=<200 \mathrm{~m}^{2} \\
\text { c) on } 2 \text { nd floor } \\
\& \mathrm{~A}=<400 \mathrm{~m}^{2} \\
\text { d) ward floor } \\
\& \mathrm{~A}=<100 \mathrm{~m}^{2} \\
\text { e) Hotel : floor with } \\
\text { sleeping rooms } \\
\& \mathrm{~A}=<200 \mathrm{~m}^{2} \\
\text { f) Apartment } \\
\& \mathrm{~A}=<200 \mathrm{~m}^{2} \\
\text { except } \\
\text { * Assembly, * Shop }\end{array}$ & $\begin{array}{l}\text { Apartment } \\
\text { a) top floor }<11 \mathrm{~m} \text {, } \\
=<4 \text { stories, } \\
\text { travel to exit }<4.5 \mathrm{~m} \\
\text { others } \\
\text { c) top floor }<11 \mathrm{~m} \text {, } \\
=<50 \mathrm{Ps} \text {. } \\
\text { d) room }=<50 \mathrm{Ps} \text {. } \\
\text { e) story }=<50 \mathrm{Ps} \text {. }\end{array}$ & $\begin{array}{l}\text { Assembly } \\
\text { a) balcony }<50 \text { Ps. } \\
\text { Hotel, Apartment } \\
\text { b) }=<4 \text { stories, } \\
=<4 \text { living units per } \\
\text { story, sprinkled } \\
\text { Office } \\
\text { c)room } / \text { area }<100 \mathrm{Ps} \text {. } \\
\text { travel to outside }<30 \mathrm{~m} \\
\text { d) }=<3 \text { stories, } \\
\text { each story }<30 \mathrm{Ps} \text {., } \\
\text { travel to outside }<30 \mathrm{~m}\end{array}$ \\
\hline
\end{tabular}

\section{CONDITIONS ALLOWED IN CASE OF SINGLE STAIRWAY}

In principle, building codes require two or more stairways as the vertical escape routes in multistory buildings. However, it is allowed to have single stairway under certain conditions since it is not practical to require two or more stairways to all buildings. Table 2 summarizes the conditions associated with the relaxation of requirements of two or more exits ${ }^{1}$.

From Table 2, it can be recognized that basically three main factors are involved when a single stairway is allowed, i.e., number of occupants on a floor, number of floors and characteristic of occupants. Other different factors are also taken into account in different codes. In average, the maximum number of occupants are limited to 50 , but the number is limited to a smaller value for buildings of residential or medical care uses. With this restriction, goes the limitation of number of floors, or building height, which differs somewhat in different codes. This limitation is considered to be associated with the chance of rescue by fire brigades.

Such concurrent limitations on occupants number on a floor and number of floors are followed by limitation of total occupants number in a building. The total number of occupants allowed to be accommodated on the second and upper floors in a building ranges from 50 to 400 depending on use of buildings and different codes. The type of buildings in which a large number of occupants are allowed are likely to be those which have no sleeping facility.

\section{EXPECTED NUMBER OF OCCUPANTS UNABLE TO ESCAPE ASSOCIATED WITH SINGLE MEANS OF ESCAPE}

\subsection{Theoretical Consideration}

Common path in a corridor and a single stairway have the same issue from the viewpoint of evacuation safety, that is, occupants are trapped by fire when the fire breaks out in a space on the way to the exit.

\section{Expected number of occupants unable to escape due to common path}

The typical plan to which the limitation of common path applies is shown in Figure 3. Our interest is how the risk on evacuation is related with common path length. Let $n$ be the number of rooms along the corridor having only one escape direction to a stairway. The escape from a room is impeded when a fire breaks out between the room and the stairway, grows to a hazardous fire and ejects flames or hot gases to the corridor through open doorways. Probability of such an event to 


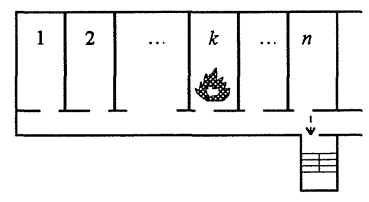

FIGURE $3 n$ rooms along a corridor having only one escape route to a stairway

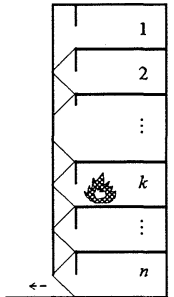

FIGURE $4 \quad n$ stories high building having a single stairway

occur for an arbitrary room $k$, which we call here "Escape route obstruction probability" can be given as

$P(k)=p 1(k) \cdot p 2(k) \cdot p 3(k)$

where $\quad p l(k)$ : probability of fire occurrence in the room

$p 2(k)$ : probability that the fire grows to a hazardous fire

$p 3(k)$ : probability that the door is left open in fire

Next, letting $Q(i)$ be the number of occupants in room $i$, the expected number of occupants who are unable to escape to the stairway $e$ for each potential room of origin $k(>1)$ is calculated as

$e(k)=\{Q(1)+Q(2)+\cdots+Q(k-1)\} P(k)=\left\{\sum_{i=1}^{k-1} Q(i)\right\} P(k)$

respectively.

Hence, the total expected number $E$ which takes into account the possibility of fire occurrence in every room is given as

$E=\sum_{k=2}^{n}\left\{\sum_{i=1}^{k-1} Q(i)\right\} P(k)$

At the stage of designing building plan, it will be likely that conditions of such rooms as above are practically regarded as uniform, that is, $P(k)=P$ and $Q(i)=Q$ in Eqn.(2), then the total expected number $E$ is calculated simply as

$E=\frac{n(n-1)}{2} P Q$

The value of $n$ is dependent on the specific plan, and $Q$ may be evaluated from the use and the area of the room. It would be desirable that the probability $P$ be obtained based on fire statistics, but currently ample statistical data is not available for the probabilities included in the right hand side of Eqn.(1), although $p 1$ and $p 2$ could be roughly estimated. As it is expected to be difficult to determine the absolute value of $P$, some other way must be sought for handling this factor.

Expected number of occupants unable to escape due to single stairway

Next, let's consider a building consisting of a single stairway and multiple floors as shown in Figure 4. Although the problem in this case may involve some difference from common path, for instance, the primary threat to evacuation in stairway is more smoke filling than hot gases ejection from door, the issues associated with a single stairway and common path of corridors are considered to be much similar. Hence the same consideration and the equations (1) - (3) may be extended to use for the problem of a single stairway. 


\subsection{Some Consideration on Effect of Factors}

\section{Number of occupants}

The provisions of common path length in any country does not explicitly take into account the variables such as $n$ and $Q$. However, in case of the assemblies and offices in the U.S.A., the limitation of common path length is relaxed when the number of occupants is low. This is considered to be rational because, as can be readily recognized from Eqn.(3), the expected number of occupants unable to escape decreases proportionally to the reduction of the number of occupants.

The expected number $E$ increases drastically with number of rooms $n$ if the number of occupants in a room $Q$ is the same. For instance, $E$ increases by 6 fold if $n$ is doubled from 2 to 4 . If the total number of occupants $n Q$ is the same, the expected number $E$ increases proportionally to the number of rooms $n-1$.

\section{Fire suppression system}

In the building codes of the U.S. the limitation of common path length is relaxed when the building is sprinklered. This provision may be justified by considering that sprinklers have the effect to reduce the probability that a fire develops to a hazardous level, that is, $p 2$ in Eqn.(1).

According to the statistics in the U.S. and Canada, the probability of flashover occurrence is reduced to about $1 / 4-1 / 5$ by the installation of sprinkler system ${ }^{3}$. Because the expected number of trapped occupants should be the same with and without a sprinkler system, then we got

$$
\frac{n(n-1)}{2} Q P=\frac{n_{s p}\left(n_{s p}-1\right)}{2} Q P_{s p}
$$

Letting the ratio of the probability of flashover occurrence be $1 / 4$, then we got

$$
\frac{P_{s p}}{P}=\frac{n(n-1)}{n_{s p}\left(n_{s p}-1\right)} \approx \frac{1}{4}
$$

where $\quad n_{s p}$ : number of rooms in sprinklered condition

$P_{s p}$ : fire probability in sprinklered condition

Based on Eqn.(6), for $n>2$, the value of $n_{s p} / n$ lies between 1.7-2.0. The number of rooms along the corridor forming the common path is considered to be about in proportion to the common path length. Hence, it follows that common path length can be approximately doubled without lowering the safety level of evacuation if the relevant part is sprinklered. In this sense, the U.S. standard for common path length, which relax the length by the equipment of sprinkler system, is thought to be reasonable.

\section{CRITERION ALTERNATIVE TO EXISTING STANDARDS ON SINGLE MEANS OF ESCAPE}

\subsection{Consideration on Some Other Factors}

As we have seen in the above, Eqn.(3) can take into account some of the factors which have been incorporated in the existing standards associated with common path length, such as number of occupants, sprinkler system and so forth, by fairly logical manners. But as can be seen in Table 2, some other factors have been taken into account in the existing codes. Hence, we should consider these factors also. They are particularly as follows:

Rescue by fire brigade

Single stairway is basically allowed for relatively low-rise buildings. This implies that the possibly 
of rescue by fire brigade using fire ladder or some other means of escape are taken into account in case the built-in means of escape, such as stairway and corridor, are made unavailable by fire.

On the other hand, rescue by fire brigade seems to be disregarded in the provisions for common path length in most building codes. The building standards law of Japan is the only code that prescribes different length of common path depending on height of floor, perhaps for some other reason. However, it will be logical that the factor of rescue is considered in common path.

\section{Degree of fire protection of escape route}

In France, a single stairway is allowed if the stairway is protected properly from fire and smoke, including being opened to outdoor air. In principle, a single stairway should be sufficient if it is perfectly free from hazards due to fire. However, perfectly protected stairways are seldom found in real buildings so the level of safety varies depending on the degree of protection. More generally, degree of protection of stairways and corridors should be added as a factor to the assessment by Eqn.(3). In most cases, corridor is closer than stairway to the room of origin, so direct impact of fire is stronger in corridors than in stairway. However, degree of protection of corridors from ejecting door jet may be significantly higher than ordinary corridor in some cases. For instance, if a corridor is wide enough, as like a lobby, it will be possible to pass in front of a doorway ejecting hot gases from the room of fire origin.

\subsection{Proposed Criterion}

Considering the factors mentioned in the above, Eqn.(3) should be slightly modified as

$$
E=\left\{\sum_{k=2}^{n}\left\{\sum_{i=1}^{k-1} Q(i) \varphi(i)\right\} P(k)\right\} \delta
$$

where $\varphi(i)$ and $\delta$ are the factors regarding efficiencies of rescue by fire brigade and degree of protection of escape route on the reduction of occupants unable to escape, respectively.

It is virtually hopeless to obtain the absolute value of $P(k), \varphi(i)$ and $\delta$, however, if we consider reference conditions of building spaces having only one escape route to which maximum number of occupants is allowed by building codes, the value of $E$ has to be

$$
E \leq Q_{r e f} P^{*} \varphi^{*} \delta^{*}
$$

where $Q_{\text {ref }}$ is the maximum number of occupants, and $P^{*}, \varphi^{*}$ and $\delta^{*}$ are the values of $P(k), \varphi(i)$ and $\delta$ implicitly assumed for such a space by the codes.

Using Eqns.(7) and (8) yields the expression of the criterion as

$$
\bar{E}=\left\{\sum_{k=2}^{n}\left\{\sum_{i=1}^{k-1} Q(i) \bar{\varphi}(i)\right\} \bar{P}(k)\right\} \bar{\delta} \leq Q_{\text {ref }}
$$

where $\bar{P}(k), \bar{\varphi}(i)$ and $\bar{\delta}$ are relative factors of probability and efficiencies defined as

$$
\bar{P}(k)=P(k) / P^{*}, \quad \bar{\varphi}(i)=\varphi(i) / \varphi^{*}, \quad \bar{\delta}=\delta / \delta^{*}
$$

\subsection{Values of Parameters}

\section{Value of $Q_{\text {ref }}$}

Applying Eqn.(9) to a corridor having only one direction to stairway and $n$ rooms of the same conditions on each side as shown in Figure 5, that is, $Q(i)=Q, \bar{P}(k)=\bar{P}$ and $\bar{\varphi}(i)=\bar{\varphi}$, we have 


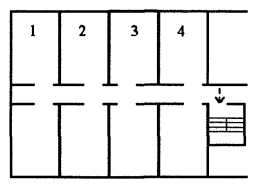

FIGURE 5 Reference condition for sleeping facilities

$2 n(n-1) Q \bar{P} \bar{\varphi} \bar{\delta} \leq Q_{\text {ref }}$

From Table 1, it is fairly evident that the common path length measured from the doorway of a room to stairway is restricted within $10 \mathrm{~m}$ in average. Four single bed rooms ( $n=4$ and $Q=1)$ may be arranged on each side of the corridor of this length in a business hotel in Japan. We adopt this as the reference condition of one way corridor with sleeping facilities. Also, considering that the limit of the common path length apply unconditionally, we may be able to let $\bar{P}=1, \bar{\varphi}=1$ and $\bar{\delta}=1$. Hence, from Eqn.(11), we have

$$
2 \times 4 \times(4-1) \times 1 \times 1 \times 1 \times 1=24 \leq Q_{\text {ref }}
$$

It is possible to adopt $Q_{\text {ref }}=24$ in Eqn.(9), which may be used in place of the common path of travel. However, we have proposed $Q_{r e f}=50$ as the maximum number of occupants in a room having a single exit in our relevant paper. ${ }^{4}$ Because the purpose of the both criteria are the same, it is convenient in practical applications that the values of the parameters are the same. For this reason, substituting $n=4, Q=1, \bar{\varphi}=1, \bar{\delta}=1$ and $Q_{r e f}=50$ to Eqn.(11), we have

$$
2 \times 4 \times(4-1) \times 1 \times \bar{P} \times 1 \times 1=24 \bar{P} \leq 50
$$

From Eqn.(13), we have $\bar{P} \approx 2$, so we regard

$\bar{P}=2$

is the value of relative escape obstruction factor of the corridor for the reference condition of sleeping facilities.

\section{Common path in corridor}

As the relative exit obstruction factor of the corridor without sleeping facilities, $\bar{P}(k)=1$ is assumed. It may be reasonable to assume that the probability of fire occurrence in a room, $p l$, is increased proportionally to room area. Noting $Q_{\text {ref }}=50$ and letting $q_{r e f}$ is density in the room of reference condition, $\bar{P}(k)$ has to be

$$
\bar{P}(k)=\frac{p(k)}{P^{*}}=\frac{\frac{Q(k)}{q(k)} p 2 \cdot p 3}{\frac{Q_{r e f}}{q_{r e f}} p 2 \cdot p^{3}}=\frac{\frac{Q(k)}{q(k)}}{\frac{Q_{r e f}}{q_{r e f}}}=\frac{A(k)}{A_{r e f}}
$$

where $q(k)$ : density in a room (person per sq. m.)

$A(\mathrm{k})$ : room area (sq. m.)

$A_{\text {ref }}:$ room area of the room of reference condition in non-sleeping use (sq. m.)

For sleeping facilities, because room areas do not differ so significant, we neglect the dependence of $p 1$ on floor area of non-sleeping use rooms. 
In summary, the relative escape route obstruction factor of corridor turns out to be

$\bar{P}(k)= \begin{cases}2 & \text { (for sleeping use) } \\ \frac{A(k)}{A_{\text {ref }}} & \text { (for non - sleeping use) }\end{cases}$

\section{Single stairway}

Now, let's apply Eqn.(9) and $Q_{\text {ref }}=50$ to a building having $n$ floors of the same conditions, that is, $\bar{P}(k)=\bar{P}, Q(i)=Q$ and $\bar{\varphi}(i)=\bar{\varphi}$, then we have

$\frac{n(n-1)}{2} Q \bar{P} \varphi \bar{\varphi} \leq 50$

From Table 2, it can be recognized that a single stairway is allowed for buildings having four or less floors and four or less dwelling units on each floor. Because the number of floor is four or less it is considered that the rescue by fire brigade is normally taken in to account, and that a high level of stairway protection is not required. Average number of occupants in a dwelling unit may be estimated as four. Hence, substituting $n=4, \delta=1$ and $Q=16$ into Eqn.(17), we have

$\frac{4 \times 3}{2} \times 16 \times \bar{P} \varphi \bar{\delta}=96 \overline{P \varphi} \leq 50$

that is, $\bar{P} \varphi=1 / 2$ for sleeping use.

Noting that 50 occupants are allowed for conditions without sleeping facilities, applying Eqn.(17) to the same configuration but non sleeping condition yields

$\frac{4 \times 3}{2} \times 50 \times \bar{P} \bar{\varphi} \bar{\delta}=300 \bar{P} \varphi \leq 50$

that is, $\bar{P} \bar{\varphi}=1 / 6$ for non-sleeping use.

A fire usually breaks out in a room on a floor. Let's imagine a fire occurred in a building for sleeping use having an unprotected single stairway. It may be reasonable to assume that the stairway will also be involved at the same time if the corridor is involved in the hazard of the fire. Using $\bar{P}=2$ in Eqn.(18) yields

$\bar{\varphi}=\frac{1 / 2}{\bar{P}}=\frac{1}{4}$

Because the efficiencies of rescue by fire brigade should depend only on building features, such as height and accessibility, $\bar{\varphi}$ should be independent of building use, so the same value as Eqn.(20) is invoked to Eqn.(19) to yield the relative stairway obstruction factor for non sleeping use as

$\bar{P}=\frac{1 / 6}{\bar{\varphi}}=\frac{2}{3}$

As discussed at common path of corridor, it may be reasonable to assume that the probability of fire break in a floor, $p l$, is increased proportionally to floor area. Noting $Q_{\text {ref }}=50, \bar{P}(k)$ has to be

$\bar{P}(k)=\frac{2}{3} \frac{A(k)}{A_{\text {ref }}}$ 
Therefore, in summary, the relative escape route obstruction factor of stairway turns out to be

$$
\bar{P}(k)= \begin{cases}2 & \text { (for sleeping use) } \\ \frac{2}{3} \frac{A(k)}{A_{\text {ref }}} & \text { (for non - sleeping use) }\end{cases}
$$

The criterion which may be used as an alternative to the existing provisions on common path length and the conditions allowed for a building having only one stairway is proposed. The criterion is summarized as follows:

$$
\left\{\sum_{k=2}^{n}\left\{\sum_{i=1}^{k-1} Q(i) \bar{\varphi}(i)\right\} \bar{P}(k)\right\} \bar{\delta} \leq Q_{\text {ref }}
$$

and the values of the associated parameters are

$\begin{array}{ll}\text { corridor: } & \bar{P}(k)= \begin{cases}2 & \text { (for sleeping use) } \\ \frac{A(k)}{A_{\text {ref }}} & \text { (for non - sleeping use) }\end{cases} \\ \text { stairway: } & \bar{P}(k)=\left\{\begin{array}{ll}2 & \text { (for sleeping use) } \\ \frac{2}{3} \frac{A(k)}{A_{\text {ref }}} & \text { (for non - sleeping use) }\end{array},\right. \\ \text { common: } & \bar{\varphi}(i)=\left\{\begin{array}{ll}1 & \text { (for no possibility of rescue) } \\ 1 / 4 & \text { (for possibility of rescue) }\end{array}, \quad \bar{\delta}=1, \quad Q_{\text {ref }}=50\right.\end{array}$

However, further consideration is needed for $\bar{\delta}$ for the various degree of escape route protection.

\section{Sample Applications}

The following examples illustrate how a single means of escape is assessed based on the above criterion. Here we assume that every room or floor has the same number of occupants for simplicity.

\subsection{Case where corridor in apartment building has single route to stairway}

Suppose that the number of occupants in one dwelling unit is four persons, i.e. $Q=4$, and every unit has no possibility of rescue by fire brigade, i.e. $\bar{\varphi}=1$. And the other parameters are : $\bar{P}(k)=2$ for sleeping use and $\bar{\delta}=1$. There are $n$ dwelling units on one side of the corridor. Hence, we have,

$\frac{n(n-1)}{2} \times 4 \times 1 \times 2 \times 1 \leq 50$

that is $n \leq 4$. For satisfying the criterion of Eqn.(23), the number of dwelling units on the corridor having only one direction to a stairway should be limited to four, as shown in Figure 6. If every unit has possibility of rescue by fire brigade, the value of $\bar{\varphi}=1 / 4$ is used, in which case the limitation of dwelling units number may be increased to seven.

6.2. Case where apartment building has a single stairway

Suppose that there are four dwelling units on one floor. The total number of occupants on the floor 


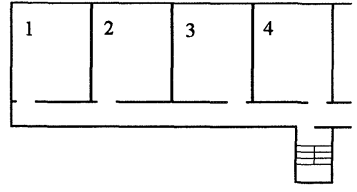

FIGURE 6 An example of common path of travel in an apartment

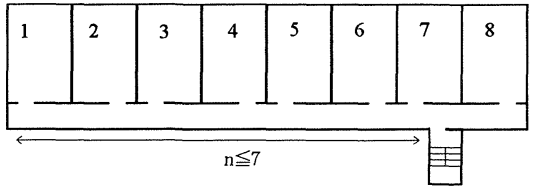

FIGURE 7 An example of three story apartment having a single stairway

is 16 persons, i.e. $Q=16$, because there are four persons in each unit. And every unit has possibility of rescue by fire brigade, i.e. $\bar{\varphi}=1 / 4$. The other parameters are : $\bar{P}(k)=2$ for sleeping use and $\bar{\delta}=1$. Hence, we have,

$\frac{n(n-1)}{2} \times 16 \times \frac{1}{4} \times 2 \times 1 \leq 50$

that is $n \leq 4$. For satisfying the criterion of Eqn.(23), the number of floors having single stairway should be limited to four.

If the number of floors is increased to five, the number of occupants on one floor should be limited to ten persons, that is, about two dwelling units per floor. On the other hand, if the number of floors is decreased to three, the number of occupants on one floor is relaxed to 33 persons, that is, about eight dwelling units per floor. However, the criterion of Eqn.(23) is not satisfied by such arrangement as the single stairway located at the end of the corridor if there are eight dwelling units on one side of the corridor. It is required that the single stairway be located somewhat inward from the end of the corridor, as shown in Figure 7.

For single escape route with sleeping facilities, other combinations satisfying the criterion of Eqn.(23) are shown in Figure 8.

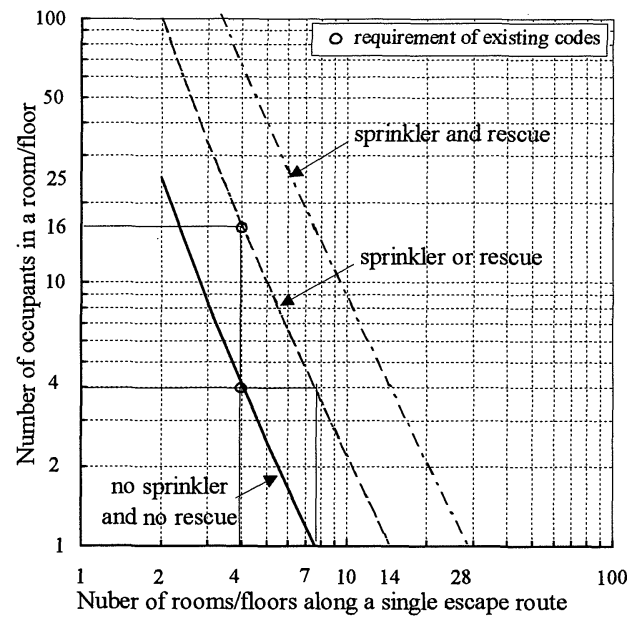

FIGURE 8 Relation between number of rooms/floors on a single means of escape and number of occupants in a room/floor with sleeping facilities 


\section{CONCLUSION}

The average level of evacuation safety will be basically the same between the proposed standard and the existing provisions. However, the advantage of the proposed standard is that it is able to take into account more factors affecting the safety of unidirectional escape within a logical context. This method will allow much more flexibility in building design without deteriorating the current level of safety.

\section{NOMENCLATURE}

$A \quad$ Area of a room or a floor (sq. m.)

$A_{\text {ref }}$ Area of a room or a floor of reference condition in non-sleeping use (sq. m.)

$E \quad$ Expected number of occupants unable to escape

$\bar{E} \quad$ Relative expected number of occupants unable to escape

p1 Probability of fire occurrence in the room

p2 Probability that the fire develops to be a hazardous fire

p3 probability that the door is left open in fire

$P \quad$ Exit obstruction probability

$P^{*} \quad$ Reference exit obstruction probability

$\bar{P} \quad$ Relative exit obstruction factor reference to $P^{*}$

$Q \quad$ Number of occupant of a room or in a floor

$Q_{r e f}$ Maximum number of occupants assumed for reference condition

$q \quad$ Density in a room or a floor (person per sq. m.)

$q_{r e f}$ Density in a room or a floor of reference condition in non-sleeping use (person per sq. $\mathrm{m}$.)

$\varphi \quad$ Efficiencies of the rescue by fire brigade

$\bar{\varphi} \quad$ Relative Efficiencies of the rescue by fire brigade

$\delta \quad$ Degree of protection of escape route

$\bar{\delta} \quad$ Relative degree of protection of escape route

\section{REFERENCE}

${ }^{1}$ Hagiwara, I and Tanaka, T, "International Comparison of Fire Safety Performance for Means of Escape", in Proceedings of the 4th International Symposium for Fire Safety Science, p.633-644, 1994

${ }^{2}$ Post-War Building Studies No.29, FIRE GRADING OF BUILDINGS, Part III. Personal Safety, Her Majesty's Stationery Office, pp.49-54, 1952.

${ }^{3}$ Gaskin,J. and Yung, D., "Canadian and U.S.A. Fire Statics for Use in the Risk-Cost Assessment Model”, Internal Report No.637, pp.4-6, 1993.1

${ }^{4}$ Tanaka, T., Hagiwara, I. and Mimura, Y., "Requirements of two or more exits in rooms, A consideration on the safety performance of two way exits provisions Part 1", Journal of Architecture, Planning and Environmental Engineering, 490, 1997. (will be printed, in Japanese) 